\title{
Thalidomide and its derivatives: emerging from the wilderness
}

\author{
J N Gordon, P M Goggin
}

Postgrad Med J 2003;79:127-132

Forty years on from its worldwide withdrawal, thalidomide is currently undergoing a remarkable renaissance as a novel and powerful immunomodulatory agent. Over the last decade it has been found to be active in a wide variety of inflammatory and malignant disorders where conventional therapies have failed. Recently, considerable progress has been made in elucidating its complex mechanisms of action, which include both anticytokine and antiangiogenic properties. However, in addition to its well known teratogenic potential, it has a significant side effect profile that leads to cessation of treatment in up to $30 \%$ of subjects. In response to this, two new classes of potentially safer and non-teratogenic derivatives have recently been developed. This review summarises the biological effects, therapeutic applications, safety profile, and future potential of thalidomide and its derivatives.

See end of article for authors' affiliations

\section{Correspondence to:}

Dr J N Gordon, Mailpoint

813, Level E, South Block,

Southampton General

Hospital, Southampton

SO16 6YD, UK

i.gordon@soton.ac.uk

Submitted

3 December 2002

Accepted

3 February 2003
T halidomide was first introduced in Wes Germany in 1956 and in the rest of Europe, Australia, Canada, and South Africa in 1957. Fortuitously, its release in the United States was delayed by the Food and Drug Administration pending clarification of concerns regarding the results of neurotoxicological studies in animals. It was initially marketed as a sedative, with its rapid speed of onset, lack of hangover effect, and apparent safety after overdose making it an attractive alternative to barbiturates. In addition it was a powerful antiemetic, and was widely taken by pregnant women for the treatment of morning sickness. However, soon after its release, there followed a rapid rise in reported cases of a previously rare birth defect, phocomelia (congenital limb foreshortening). In 1961, after reports linking this to in utero thalidomide expo-

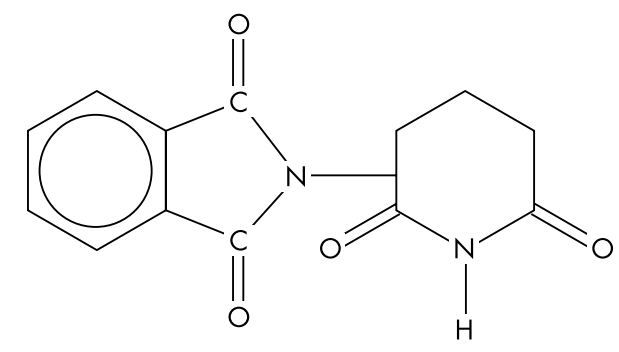

Figure 1 Structure of thalidomide. sure, the drug was withdrawn leaving a legacy of between 6000 and 10000 affected children. ${ }^{1}$

However, a few years later, the serendipitous discovery of thalidomide's anti-inflammatory potential ensured it was never entirely forgotten. In the course of treating a patient with mania and leprosy, Sheskin, an Israeli physician, administered some old supplies of thalidomide for its sedative effect. This resulted in the dramatic and virtually complete resolution of the patient's cutaneous symptoms, and was the first indication of the drug's potential. ${ }^{3}$ However, it was not until the discovery of thalidomide's antitumour necrosis factor- $\alpha$ (TNF- $\alpha$ ) activity in 1991 that interest really intensified. ${ }^{4}$ Since then, a significant body of work has now been published that has helped to gradually elucidate the mode of action, and potential uses of this unique drug.

\section{PHARMACOKINETICS}

Thalidomide, a derivative of glutamic acid, is administered clinically as a $1: 1$ racaemic mixture of its S and R isomers. It is well absorbed after oral administration with maximal plasma levels of around $1-4 \mu \mathrm{g} / \mathrm{ml}$ reached within 2-4 hours. There is some evidence to suggest that individual isomers have different biological properties with the S-isomer responsible for the immunomodulatory effects, while the R-isomer accounts for the sedative effects. ${ }^{56}$ In animal studies, both isomers caused fetal malformations when administered to the New Zealand rabbit (a species known to be sensitive to its teratogenic effects), whereas in rodents (a less sensitive species), malformations were only observed in those who received the S-isomer. ${ }^{78}$ However, in humans, the rapid chiral interconversion that occurs between the two isomers in vivo limits any potential benefit from administering a specific isomer. ${ }^{9}$ Thalidomide is eliminated by $\mathrm{pH}$ dependant spontaneous hydrolysis to multiple chemically inactive metabolites, and has a half life of approximately five hours. As there is virtually no excretion via the liver or renal pathways the risk of drug interactions is low. Specifically, it has been shown that thalidomide does not affect the metabolism of oral contraceptive pills containing norethindrone or ethinyl oestradiol. ${ }^{10}$ Thalidomide has recently been shown to be present in the semen after oral dosing. ${ }^{11}$

The structure of thalidomide is shown in fig 1 .

Abbreviations: GvHD, graft versus host disease; IFN- $\gamma$ interferon- $\gamma$; IL, interleukin; TNF- $\alpha$, tumour necrosis factor- $\alpha$ 


\section{IMMUNOLOGICAL PROPERTIES}

Thalidomide's immunomodulatory properties are complex and incompletely understood. Multiple mechanisms of action have been reported, with the best recognised being its ability to inhibit the production of TNF- $\alpha$.

In contrast with corticosteroids thalidomide can inhibit monocyte derived TNF- $\alpha$ production without downregulating interleukin (IL)-1 $\beta$, IL-2, or IL-6 production. ${ }^{42}$ Though initially thought to primarily act only on monocytes, thalidomide has since been shown to down-regulate TNF- $\alpha$ production across a broad range of cell types including T- lymphocytes, alveolar macrophages, lamina propria mononuclear cells, and microglial cells. ${ }^{13-16}$ Maximal inhibition is in the order of approximately $50 \%-70 \%$ with some variation between cell types. ${ }^{17}$ The mechanism by which thalidomide suppresses TNF- $\alpha$ production remains unclear. It appears to interfere with gene transcription or translation, and has been demonstrated to enhance TNF- $\alpha$ mRNA degradation. ${ }^{18}$ More recently it has been shown to inhibit NF-kappaB activation, a ubiquitous transcription factor that promotes the production of inflammatory cytokines, through suppressing I-kappaB kinase activity. ${ }^{19}$ Finally, there is also some evidence that in certain circumstances thalidomide may be able to augment TNF- $\alpha$ production, potentially indicating cell specific effects. ${ }^{20}$

In addition to its effects on TNF- $\alpha$ production thalidomide can influence other cytokine production. Concurrently with suppressing TNF- $\alpha$ production, thalidomide has been shown to simultaneously enhance production of IL-4 and IL-5, in effect promoting a shift from a Thl to Th2 cytokine pattern. ${ }^{21}$ Additionally, thalidomide has been shown to have a bidirectional effect on IL-12 production, a cytokine that is central to the development of an effective cellular immune response. Thalidomide suppresses IL-12 production by mitogen activated monocytes and lamina propria cells, while it enhances production when stimulated through the T-cell receptor. ${ }^{1522}$

These dichotomous results may in part be explained by the recently recognised ability of thalidomide to act as a T-cell co-stimulant under certain circumstances. The addition of thalidomide to cultures of T-cells activated through the T-cell receptor, results in an enhanced Thl response with augmented production of IL-2 and interferon- $\gamma$ (IFN- $\gamma$ ) along with an increase in cell proliferation. ${ }^{17}$ This is of interest as the ability to provoke a marked Thl response is potentially beneficial in enhancing antitumour activity. In one recent study, CC-4047, a thalidomide derivative with marked co-stimulatory activity, was able to prime protective, long lasting, tumour specific responses in a mouse model. ${ }^{24}$

Finally, a further potentially important property of thalidomide is its antiangiogenic effects. In vitro studies have shown thalidomide to be capable of inhibiting angiogenesis induced by vascular endothelial derived growth factor and basic fibroblast growth factor. ${ }^{25} 26$ A subsequent study has also shown this effect to be independent of TNF- $\alpha$ suppression. ${ }^{27}$

\section{THALIDOMIDE DERIVATIVES}

Over the last few years the re-emergence of thalidomide has awakened interest in developing structural analogues that possess its immunomodulatory properties without the associated side effects. Several such compounds have recently been developed that are up to 50000 -fold more potent than thalidomide at inhibiting TNF- $\alpha$ on a molar basis. ${ }^{17}$ They are broadly split into two main groups, dependent on their biological effects. The first class, immunomodulatory drugs, strongly inhibit TNF- $\alpha$ along with IL- $1 \beta$, IL-6, and IL- 12 while augmenting IL-10 production. They are also potent costimulators of T-cells when activated through the T-cell receptor and dramatically increase T-cell proliferation. They do not inhibit phosphodiesterase-4. The second class, selective cytokine inhibitory drugs, again potently inhibit TNF- $\alpha$, though much more selectively, having considerably less effect

\section{Box 1: Immunological effects of thalidomide}

- Switch cytokine production from Th1 to Th2 profile.

- Inhibit TNF- $\alpha$ synthesis.

- Inhibit IL-6 synthesis.

- Inhibit IL-12 synthesis.

- Inhibit IFN- $\gamma$ synthesis.

- Augment IL-4 production.

- Augment IL-10 production.

- Act as a T-cell co-stimulant.

- Augment IFN- $\gamma$ synthesis.

- Augment IL-2 synthesis.

- Augment IL-10 synthesis.

- Reduce expression of intracellular adhesion molecule-1.

- Reduce expression of vascular cell adhesion molecule-1.

- Reduce synthesis of basic fibroblast growth factor.

- Reduce synthesis of vascular endothelial derived growth factor.

on other inflammatory cytokines. They have little effect on T-cell activation, causing only a slight inhibition in T-cell proliferation. These compounds do markedly inhibit phosphodiesterase-4, though it is currently unclear how much this contributes to their biological effects. ${ }^{28}$

Importantly, preliminary results from animal studies have shown at least some of these compounds to be clinically effective, and non-toxic and non-mutagenic. ${ }^{29}{ }^{30}$ Several are now undergoing phase I and phase II clinical trials though none are currently in routine clinical use.

\section{CLINICAL APPLICATIONS Leprosy}

Erythema nodosum leprosum is an acute vasculitis seen in patients with lepromatous leprosy after antilepromatous treatment. It is characterised by a painful, ulcerative, nodular rash and systemic symptom such as fever, arthralgia, neuritis, and glomerulonephritis. Immunologically, it involves components of both a cell mediated immune response with raised IFN- $\gamma$, TNF- $\alpha$, and IL-12, and an immune complex mediated disease. Subsequent to Sheskin's original discovery several controlled and uncontrolled studies, including a World Health Organisation coordinated randomised controlled trial, have been published confirming its effectiveness. ${ }^{31}$ More recently a literature review by Sheskin in 1980 analysed data from 4552 cases and found the response rate to treatment to be $99 \%{ }^{32}$ Its effectiveness is thought to be due to its anticytokine effects with responders showing a marked reduction in serum TNF- $\alpha$ levels along with down-regulation of intracellular adhesion molecule-1 and major histocompatibility complex class II antigen expression on epidermal keratinocytes. ${ }^{33}$ Treatment can gradually be tapered afterclinical response though in many cases maintenance low dose therapy is required for a number of years.

\section{Mucocutaneous ulceration}

Thalidomide has proved to be highly effective in the treatment of both resistant oral aphthous ulceration, and HIV associated aphthous ulceration. In a placebo controlled crossover trial in patients with severe oral ulceration, $42 \%$ went into complete remission with active treatment compared with $8 \%$ on placebo. ${ }^{34}$ Similarly, in trials involving HIV associated ulceration, $55 \%$ with oral and $73 \%$ with oesophageal ulceration went into complete remission compared with $8 \%$ and $23 \%$ in the respective placebo groups. ${ }^{356}$

In Behçet's disease several uncontrolled studies have all shown thalidomide to be effective in both treatment, and prevention of recurrence of orogenital ulceration. ${ }^{37}$ However in the only placebo controlled trial, complete response rates of $9 \%$ on treatment over $0 \%$ on placebo, while statistically significant, were not particularly impressive. ${ }^{38}$ 
Irrespective of aetiology, mucocutaneous ulceration often recurs after cessation of therapy, necessitating recurrent courses of treatment.

\section{Crohn's disease}

Thalidomide's potential as a treatment for inflammatory bowel disease was first reported in 1979 after its successful use in a patient with severe unresponsive ulcerative colitis. ${ }^{39} \mathrm{How}$ ever it is only recently, after the discovery of the central role of TNF- $\alpha$ in the pathogenesis of Crohn's disease, that attention has returned to it. In 1999 two papers were published simultaneously, in which patients with steroid resistant or steroid refractory Crohn's disease were successfully treated with oral thalidomide for a total of 12 weeks. ${ }^{40}{ }^{41}$ Subsequently, two other open label trials have now been published..$^{15} 42$ In total in the four trials 49 patients have been treated. Overall $85 \%$ of patients who completed the trials responded to treatment, though a relatively high number, $27 \%$, withdrew due to the development of adverse events. Preliminary reports also indicate thalidomide to be effective as maintenance treatment after induction of remission with infliximab. ${ }^{43}$

\section{Wasting and cancer cachexia}

Anorexia and cachexia associated with chronic illness is known to be in part mediated through a Thl immune response with enhanced production of proinflammatory cytokines such as TNF- $\alpha$, IL-1 $\beta$, and IL-6. It is associated with a shortened life expectancy in cancer sufferers. Thalidomide has been shown to be able to retard or reverse this weight loss in a number of conditions. Randomised controlled trials have confirmed its efficacy in reversing weight loss in patients with HIV associated wasting and in patients with active pulmonary tuberculosis. ${ }^{44}{ }^{45}$ Encouraging results have been also been published in a pilot study of patients with cachexia associated with advanced oesophageal malignancy. ${ }^{46}$ However, to date no randomised controlled trials have yet been reported. Finally, in several uncontrolled preliminary studies the combination of thalidomide's antiemetic, analgesic, and sedative effects have been effective in the palliation of patients with terminal malignancy and otherwise intractable symptoms. ${ }^{47}$

\section{Haematological malignancies}

Angiogenesis is important in the progression of haematological malignancies such as leukaemia, lymphoma, myelodysplasia, and myeloma. In view of this there has been considerable interest in the use of drugs such as thalidomide that possess immunomodulatory and antiangiogenic properties. The most promising results to date have been in the treatment of multiple myeloma. In 1999 Singhal et al reported a 32\% response rate in 84 patients with high risk refractory myeloma treated with thalidomide. ${ }^{48}$ Several further studies have now confirmed these findings with published response rates of $25 \%-35 \%$ with responders showing a decrease in plasma and bone marrow levels of basic fibroblast growth factor, vascular endothelial derived growth factor, and TNF- $\alpha{ }^{49}{ }^{50}$ Polymorphisms of the TNF- $\alpha$ gene promoter correlate with pretreatment serum TNF- $\alpha$ levels, and appear able to predict outcome with high producers more likely to respond to therapy." Thalidomide should now be recommended as standard treatment for patients with advanced refractory multiple myeloma. Furthermore, encouraging results have also been obtained in phase I/II pilot studies using the immunomodulatory drugs, though no peer reviewed papers have been published to date.

Thalidomide may also be effective in the treatment of high risk myelodysplasia, acute and chronic myeloid leukaemia, and other myeloproliferative disorders. In the largest published trial including 83 patients with refractory anaemia secondary to myelodysplasia $31 \%$ of those completing treatment responded with $20 \%$ becoming independent of transfusions. ${ }^{52}$

\section{Solid organ malignancies}

Responses have been seen in up to a third of patients with Kaposi's sarcoma, and in some patients with renal cell carcinoma, and high grade glioma, though in recent studies it was of little benefit in patients with advanced breast cancer and advanced melanoma. ${ }^{53}$ In combination therapy with irinotecan for advanced colorectal cancer, it eliminated the side effects of chemotherapy allowing patients to complete treatment. ${ }^{54}$ However there have recently been several reports of a high incidence of thromboembolic disease in patients with advanced cancer treated with thalidomide. ${ }^{55}$ Consequently, though it does appear to possess some activity against solid tumours the risk/benefit ratio as a single agent is marginal and it cannot currently be recommended. Further studies are currently underway to assess its potential in combination therapy.

\section{Dermatological conditions}

Thalidomide has proved to be an effective antipruritic agent in a number of dermatological disorders. It has been used successfully in the treatment of uraemic pruritus in patients undergoing haemodialysis, and in the treatment of prurigo nodularis which is associated with intense itching. It has also been used successfully in the treatment of a number of other dermatological conditions resistant to conventional therapies including porphyria cutanea tarda, discoid lupus, actinic prurigo, cutaneous hystiocytosis $\mathrm{X}$, and pyoderma gangrenosum. ${ }^{56}$

On the basis of its anti-TNF- $\alpha$ activity thalidomide was also administered in a randomised placebo controlled trial to patients with toxic epidermal necrolysis, a dramatic, life threatening condition with a 30\% mortality. Though only small numbers were involved, the trial was stopped early due to an excess of deaths in thalidomide arm $(p=0.007)$. The authors speculate this may have been due to a paradoxical enhancement of TNF- $\alpha$ production..$^{57}$

\section{Graft versus host disease (GvHD)}

Chronic GvHD occurs in up to $40 \%$ of patients after allogenic bone marrow transplant. It is characterised by a sicca-like syndrome that predominantly affects the skin, gastrointestinal tract, liver, and immune system. Animal studies using a rat major histocompatibility complex mismatch model have shown thalidomide to be effective in both the prophylaxis and treatment of GvHD. ${ }^{58}$ Subsequent clinical studies using thalidomide for refractory chronic GvHD have given encouraging results, with response rates in the region of $38 \%$ to $59 \%$. ${ }^{59}$ However, a more recent randomised controlled trial failed to show any clear benefit from the addition of thalidomide over and above that of conventional immunosuppressive therapy. ${ }^{61}$

\section{Rheumatological disorders}

Results from animal studies indicate that thalidomide and its derivatives are effective in inhibiting the development of arthritis in specific mouse models. ${ }^{62}$ However after an initial enthusiastic report where 12 out of 17 patients with refractory arthritis responded to treatment, results from more recent clinical studies have shown little or no benefit. ${ }^{63-65}$

There have been several small case series of patients with refractory sarcoidosis, scleroderma, and cutaneous lupus who responded to thalidomide. ${ }^{66-68}$ However no convincing large case series or randomised controlled trials have yet been published, and currently there is not enough reliable evidence to report efficacy.

Conditions for which thalidomide has shown potential are shown in box 2 .

\section{TERATOGENICITY}

Thalidomide is well known to be extremely teratogenic. The effects are species dependent as seen from animal studies 
Box 2: Conditions for which thalidomide has shown potential

Gastrointestinal

- Behçet's disease.

- Recurrent aphthous oral ulceration.

- HIV associated oral and oesophageal ulceration.

- Crohn's disease.

Rheumatological

- Rheumatoid arthritis.

- Systemic lupus erythematosis

- Discoid lupus erythematosis.

- Sjögren's syndrome.

- Sarcoidosis.

Dermatological

- Leprosy.

- Actinic prurigo.

- Prurigo nodularis.

- Uraemic pruritus.

- Pyoderma gangrenosum.

Haematological malignancy

- Multiple myeloma.

- Myelodysplasia.

- Acute myeloid leukaemia/chronic myeloid leukaemia.

\section{Solid tumours}

- Malignant glioma.

- Kaposi's sarcoma.

- Prostatic carcinoma.

- Colorectal carcinoma.

- Renal cell carcinoma.

Cachexia and weight loss

- HIV associated wasting.

- Cancer cachexia.

- Tuberculosis associated wasting

\section{Miscellaneous}

- Graft versus host disease

- Intractable insomnia.

- Neuropathic pain.

where the New Zealand rabbit fetus develops typical abnormalities after exposure, while the rat fetus remains largely unaffected. ${ }^{69}$ In humans it has been estimated there is a $10 \%-50 \%$ risk of subsequent birth defects after in utero exposure, with even a single $50 \mathrm{mg}$ dose capable of causing severe abnormalities if administered during the first trimester of pregnancy. ${ }^{70}$ The most frequent fetal abnormalities seen in humans are phocomelia (short limbs) or amelia (absent limbs). Other common abnormalities include central skeletal abnormalities, malformation of internal organs, and craniofacial abnormalities. The term mortality rate in affected cases is reported to be around $40 \%$, mostly in relation to failure of major organ formation. ${ }^{7}$

The specific mechanism or mechanisms responsible for thalidomide's teratogenicity are currently unknown. In one study thalidomide has been shown to cause free radical mediated oxidative damage to embryonic cellular DNA in rabbits, ${ }^{72}$ while in another it appears to interact with the adhesion molecule $\mathrm{N}$-cadherin, disturbing cellular recognition and migration during embryogenesis. ${ }^{73}$ It has also been proposed that thalidomide may, by binding to specific promoter sites, inhibit the transcription of genes involved in normal developmental angiogenesis. $^{74}$

\section{OTHER SIDE EFFECTS}

Peripheral neuropathy is the most serious side effect to occur with a reported incidence of anywhere from $1 \%$ to $70 \%$

\section{Box 3: Side effects}

Teratogenicity

- One $50 \mathrm{mg}$ dose can produce severe defects.

Peripheral neuropathy

- Predominantly sensory.

- Axonal degeneration.

- Occasionally permanent.

\section{Somnolence}

- Virtually universal.

- Administer at bedtime to reduce effect.

- Tolerance develops.

\section{Constipation}

- Laxatives commonly needed.

- Occasionally severe.

Macular rash

- Self limiting on stopping treatment.

- More common in HIV positive patients.

\section{Neutropenia}

- Rare.

- More common in HIV positive patients.

dependent on definition and the underlying disorder. ${ }^{56} \mathrm{~A}$ recent large prospective study reported an incidence of 10\% with age and cumulative dose being contributory factors, though another retrospective study did not find a link with either daily or cumulative dose. ${ }^{75} 76$ It characteristically presents as a painful or burning sensory neuropathy in association with mild proximal muscle weakness. Weakness rapidly resolves after cessation of therapy, though sensory changes are typically slow to recover and in some cases may be irreversible. The predominant underlying pathological lesion is axonal degeneration.

Other recognised side effects of thalidomide include drowsiness, macular rash, constipation, dizziness, decreased libido, mild endocrine effects, and rarely neutropenia (see box 3 ).

\section{PRECAUTIONS FOR USE}

In view of the serious risk of teratogenicity the worldwide availability of thalidomide is extremely limited. In the United States it is only commercially available through the manufacturer regulated System for Thalidomide Education and Prescribing Safety (STEPS) programme. In the UK it is available on a named patient basis in accordance with section 5(1) of the Medicines Act 1968.

It should only be used for the treatment of severe disabling conditions causing unacceptable interference with normal life, when other treatments have been tried and failed. Patients should sign a consent form before starting treatment, and specific detailed contraceptive precautions must be adhered to. Patients should undergo regular clinical examination while on treatment and be advised to stop treatment if they develop neuropathic symptoms. Baseline nerve conduction studies may be useful before initiating therapy. Excessive daytime somnolence can be minimised by bedtime dosing, and usually resolves over the first few weeks of therapy.

Anyone involved in prescribing thalidomide should refer to the published guidelines on the clinical use and dispensing of the drug in the UK for more detailed information. ${ }^{77}$

Precautions for the prevention of pregnancy are shown in box 4 .

\section{CONCLUSION}

Despite its inherent dangers, thalidomide clearly represents an important therapeutic option in selected patients. Its most 


\section{Box 4: Precautions for the prevention of pregnancy}

During treatment any women of childbearing potential* must:

- Be made aware of the risk of birth defects and other serious side effects associated with thalidomide.

- Complete a written consent form.

- Provide a negative pregnancy test within one week before starting thalidomide, and undergo regular pregnancy testing while on treatment.

- Agree to abstain from intercourse or use two forms of contraception at the same time, which must begin one month before starting thalidomide and continued for at least one month after stopping treatment.

(A) Sterilisation (male or female) is not $100 \%$ reliable and as such an additional method of contraception must be used.

(B) Women who do not normally practice contraception because of a history of infertility should do while taking thalidomide.

- Male patients must be instructed to use a condom every time they have intercourse even if they have undergone vasectomy.

- No more than one month's supply of thalidomide should be prescribed at any given time.

*A woman of childbearing potential is defined as any women under the age of 54 who has not undergone hysterectomy, or any woman aged 54 or over, who is still having natural periods or whose periods finished less than one year ago.

significant risks, namely teratogenicity and peripheral neuropathy, can be minimised by judicious prescribing on a case by case basis, with strict adherence to published guidelines. It is hoped that in the future, safer, non-teratogenic derivatives may be able to replace its use.

\section{Authors' affiliations}

J N Gordon, Division of Infection, Inflammation, and Repair, University of Southampton, Southampton General Hospital, Southampton

P M Goggin, Department of Gastroenterology, Queen Alexandra

Hospital, Portsmouth

\section{REFERENCES}

1 McBride W. Thalidomide and congenital abnormalities. Lancet $1961 ;$ ii: 1358

2 Lenz W. Fragen aus der Praxis: kindliche Missbildungen nach Medikament Einnahme wahrend der Graviditat? Dtsch Med Wochenschr 1961:86:2555-6.

3 Sheskin J. Further observation with thalidomide in lepra reactions. Lepr $\operatorname{Rev} 1965 ; 36: 183-7$

4 Sampaio EP, Sarno EN, Galilly R, et al. Thalidomide selectively inhibits tumor necrosis factor alpha production by stimulated human monocytes. $J$ Exp Med 1991;173:699-703.

5 Nishimura K, Hashimoto Y, Iwasaki S. (S)-form of

alpha-methyl-N(alpha)- phthalimidoglutarimide, but not its (R)-form, enhanced phorbol ester-induced tumor necrosis factor-alpha production by human leukemia cell HL-60: implication of optical resolution of thalidomidal effects. Chem Pharm Bull (Tokyo) 1994;42:1 157-9.

6 Hoglund P, Eriksson T, Bjorkman S. A double-blind study of the sedative effects of the thalidomide enantiomers in humans. J Pharmacokinet Biopharm 1998:26:363-83.

7 Fabro S, Smith RL, Williams RT. Toxicity and teratogenicity of optical isomers of thalidomide. Nature 1967;215:296.

8 Blaschke G, Kraft H, Fickentscher K, et al. Chromatographic separation of racemic thalidomide and teratogenic activity of its enantiomers. Arzneimittelforschung 1979;29:1640-2.

9 Eriksson T, Bjorkman S, Hoglund P. Clinical pharmacology of thalidomide. Eur J Clin Pharmacol 2001:57:365-76.

10 Trapnell CB, Donahue SR, Collins JM, et al. Thalidomide does not alter the pharmacokinetics of ethinyl estradiol and norethindrone. Clin Pharmacol Ther 1998;64:597-602.

11 Teo SK, Harden JL, Burke AB, et al. Thalidomide is distributed into human semen after oral dosing. Drug Metab Dispos 2001;29:1355-7.

12 Rowland TL, McHugh SM, Deighton J, et al. Differential regulation by thalidomide and dexamethasone of cytokine expression in human peripheral blood mononuclear cells. Immunopharmacology 1998;40: 11-20.
13 Rowland TL, McHugh SM, Deighton J, et al. Selective down-regulation of T cell- and non-T cell-derived tumour necrosis factor alpha by thalidomide: comparisons with dexamethasone. Immunol Lett 1999;68:325-32.

14 Tavares JL, Wangoo A, Dilworth P, et al. Thalidomide reduces tumour necrosis factor-alpha production by human alveolar macrophages. Respir Med 1997;91:31-9

15 Bauditz J, Wedel S, Lochs $\mathrm{H}$. Thalidomide reduces tumour necrosis factor alpha and interleukin 12 production in patients with chronic active Crohn's disease. Gut 2002; 50: 196-200.

16 Peterson PK, Hu S, Sheng WS, et al. Thalidomide inhibits tumor necrosis factor-alpha production by lipopolysaccharide- and lipoarabinomannan-stimulated human microglial cells. J Infect Dis 1995; 172:1 137-40.

17 Corral LG, Kaplan G. Immunomodulation by thalidomide and thalidomide analogues. Ann Rheum Dis 1999;58(suppl I):1107-13.

18 Moreira AL, Sampaio EP, Zmuidzinas A, et al. Thalidomide exerts its inhibitory action on tumor necrosis factor alpha by enhancing mRNA degradation. J Exp Med 1993;77:1675-80.

19 Keifer JA, Guttridge DC, Ashburner BP, et al. Inhibition of NF-kappa B activity by thalidomide through suppression of IkappaB kinase activity. J Biol Chem 2001;276:22382-7.

20 Shannon EJ, Sandoval F. Thalidomide can be either agonistic or antagonistic to LPS evoked synthesis of TNF-alpha by mononuclear cells. Immunopharmacol Immunotoxicol 1996:18:59-72.

21 McHugh SM, Rifkin IR, Deighton J, et al. The immunosuppressive drug thalidomide induces Thelper cell type 2 (Th2) and concomitantly inhibits Th 1 cytokine production in mitogen- and antigen-stimulated human peripheral blood mononuclear cell cultures. Clin Exp Immunol 1995;99:160-7.

22 Moller DR, Wysocka M, Greenlee BM, et al. Inhibition of IL-12 production by thalidomide. J Immunol 1997;159:5157-61

23 Haslett PA, Klausner JD, Makonkawkeyoon S, et al. Thalidomide stimulates T cell responses and interleukin 12 production in HIV-infected patients. AIDS Res Hum Retroviruses 1999;15:1169-79.

24 Dredge K, Marriott JB, Todryk SM, et al. Protective antitumor immunity induced by a costimulatory thalidomide analog in conjunction with whole tumor cell vaccination is mediated by increased Th 1 -type immunity. $J$ Immunol 2002;168:4914-19.

25 D'Amato RJ, Loughnan MS, Flynn E, et al. Thalidomide is an inhibitor of angiogenesis. Proc Natl Acad Sci U S A 1994;91:4082-5.

26 Kruse FE, Joussen AM, Rohrschneider K, et al. Thalidomide inhibits corneal angiogenesis induced by vascular endothelial growth factor. Graefes Arch Clin Exp Ophthalmol 1998;236:461-6.

27 Kenyon BM, Browne F, D'Amato RJ. Effects of thalidomide and related metabolites in a mouse corneal model of neovascularization. Exp Eye Res 1997:64:971-8.

28 Corral LG, Haslett PA, Muller GW, et al. Differential cytokine modulation and $\mathrm{T}$ cell activation by two distinct classes of thalidomide analogues that are potent inhibitors of TNF-alpha. J Immunol $1999 ; 163: 380-6$

29 Oliver SJ, Freeman SL, Corral LG, et al. Thalidomide analogue CC1069 inhibits development of rat adjuvant arthritis. Clin Exp Immunol 1999:118:315-21.

30 Marriott JB, Westby M, Cookson S, et al. CC-3052: a water-soluble analog of thalidomide and potent inhibitor of activation-induced TNF-alpha production. J Immunol 1998;161:4236-43

31 lyer CG, Languillon J, Ramanujam K, et al. WHO co-ordinated short-term double- blind trial with thalidomide in the treatment of acute lepra reactions in male lepromatous patients. Bull World Health Organ 1971:45:719-32.

32 Sheskin J. The treatment of lepra reaction in lepromatous leprosy. Fifteen years' experience with thalidomide. Int J Dermatol 1980;19:318-22.

33 Sampaio EP, Hernandez MO, Carvalho DS, et al. Management of erythema nodosum leprosum by thalidomide: thalidomide analogues inhibit $M$. leprae-induced TNFalpha production in vitro. Biomed Pharmacother 2002:56:13-19.

34 Revuz J, Guillaume JC, Janier M, et al. Crossover study of thalidomide vs placebo in severe recurrent aphthous stomatitis. Arch Dermatol placebo in severe

35 Jacobson JM, Greenspan JS, Spritzler J, et al. Thalidomide for the treatment of oral aphthous ulcers in patients with human immunodeficiency virus infection. National Institute of Allergy and Infectious Diseases AIDS Clinical Trials Group. N Engl J Med 1997:336:1487-93.

36 Jacobson JM, Spritzler J, Fox L, et al. Thalidomide for the treatment of esophageal aphthous ulcers in patients with human immunodeficiency virus infection. National Institute of Allergy and Infectious Disease AIDS Clinical Trials Group. J Infect Dis 1999;180:61-7.

37 Shek LP, Lim DL. Thalidomide in Behçet's disease. Biomed Pharmacother 2002;56:31-5.

38 Hamuryudan $\mathbf{V}$, Mat $C$, Saip $S$, et al. Thalidomide in the treatment of the mucocutaneous lesions of the Behcet syndrome. A randomized, double-blind, placebo- controlled trial. Ann Intern Med 1998; 128:443-50

39 Waters MF, Laing AB, Ambikapathy A, et al. Treatment of ulcerative colitis with thalidomide. BM 1979;i:792.

40 Ehrenpreis ED, Kane SV, Cohen LB, et al. Thalidomide therapy for patients with refractory Crohn's disease: an open-label trial. Gastroenterology 1999:117:1271-7.

41 Vasiliauskas EA, Kam LY, Abreu-Martin MT, et al. An open-label pilot study of low- dose thalidomide in chronically active, steroid-dependent Crohn's disease. Gastroenterology 1999;117:1278-87. 
42 Bariol C, Meagher AP, Vickers CR, et al. Early studies on the safety and efficacy of thalidomide for symptomatic inflammatory bowel disease. J Gastroenterol Hepatol 2002;17:135-9.

43 Sabate JM, Villarejo J, Lemann $M$, et al. An open-label study of thalidomide for maintenance therapy in responders to infliximab in chronically active and fistulizing refractory Crohn's disease. Aliment Pharmacol Ther 2002;16:1117-24.

44 Kaplan G, Thomas S, Fierer DS, et al. Thalidomide for the treatment of AIDS-associated wasting. AIDS Res Hum Retroviruses 2000;16:134555

45 Tramontana JM, Utaipat U, Molloy A, et al. Thalidomide treatment reduces tumor necrosis factor alpha production and enhances weigh gain in patients with pulmonary tuberculosis. Mol Med 1995;1:384-97.

46 Khan ZH, Simpson E, Cole AT, et al. Oesophageal cancer and cachexia: the effects of thalidomide on weight loss and lean body mass in a sequential (metabolic) study. Gut 2002;50(suppl II):A4

47 Peuckmann V, Fisch $M$, Bruera E. Potential novel uses of thalidomide: focus on palliative care. Drugs 2000;60:273-92.

48 Singhal S, Mehta J, Desikan R, et al. Antitumor activity of thalidomide in refractory multiple myeloma. N Engl J Med 1999;341:1565-71.

49 Rajkumar SV, Gertz MA, Kyle RA, et al. Current therapy for multiple myeloma. Mayo Clin Proc 2002;77:813-22.

50 Dmoszynska A, Bojarska-Junak A, Domanski D, et al. Production of proangiogenic cytokines during thalidomide treatment of multiple myeloma. Leuk Lymphoma 2002;43:401-6.

51 Neben K, Mytilineos J, Moehler TM, et al. Polymorphisms of the tumor necrosis factor-alpha gene promoter predict for outcome after thalidomide therapy in relapsed and refractory multiple myeloma. Blood 2002:100:2263-5

52 Raza A, Meyer P, Dutt D, et al. Thalidomide produces transfusion independence in long-standing refractory anemias of patients with myelodysplastic syndromes. Blood 2001;98:958-65.

53 Singhal S, Mehta J. Thalidomide in cancer. Biomed Pharmacother 2002;56:4-12.

54 Govindarajan R, Heaton KM, Broadwater $R$, et al. Effect of thalidomide on gastrointestinal toxic effects of irinotecan. Lancet 2000;356:566-7.

55 Bennett C, Schumock G, Desai A, et al. Thalidomide-associated deep vein thrombosis and pulmonary embolism. Am J Med 2002;1 13:603-6.

56 Tseng S, Pak G, Washenik K, et al. Rediscovering thalidomide: a review of its mechanism of action, side effects, and potential uses. J Am Acad Dermatol 1996:35:969-79.

57 Wolkenstein P, Latarjet J, Roujeau JC, et al. Randomised comparison of thalidomide versus placebo in toxic epidermal necrolysis. Lancet 1998;352:1586-9

58 Vogelsang GB, Hess AD, Santos GW. Thalidomide for treatment of graft-versus-host disease. Bone Marrow Transplant 1988;3:393-8.

59 Browne PV, Weisdorf DJ, Defor T, et al. Response to thalidomide therapy in refractory chronic graft-versus-host disease. Bone Marrow Transplant 2000;26:865-9.
60 Vogelsang GB, Farmer ER, Hess AD, et al. Thalidomide for the treatment of chronic graft-versus-host disease. NEngl J Med 1992:326:1055-8.

61 Arora M, Wagner JE, Davies SM, et al. Randomized clinical trial of thalidomide, cyclosporine, and prednisone versus cyclosporine and prednisone as initial therapy for chronic graft-versus-host disease. Biol Blood Marrow Transplant 2001;7:265-73.

62 Oliver SJ, Cheng TP, Banquerigo ML, et al. The effect of thalidomide and 2 analogs on collagen induced arthritis. J Rheumatol 1998:25:964-9.

63 Gutierrez-Rodriguez 0 , Starusta-Bacal P, Gutierrez-Montes $O$ Treatment of refractory rheumatoid arthritis---the thalidomide experience. $J$ Rheumatol 1989;16:158-63.

64 Huizinga TW, Dijkmans BA, van der Velde EA, et al. An open study of pentoxyfylline and thalidomide as adjuvant therapy in the treatment of rheumatoid arthritis. Ann Rheum Dis 1996;55:833-6.

65 Keesal N, Wasserman M, Bookman A, et al. Thalidomide in the treatment of refractory rheumatoid arthritis. J Rheumatol 1999;26:2344-7

66 Baughman RP, Judson MA, Teirstein AS, et al. Thalidomide for chronic sarcoidosis. Chest 2002;122:227-32.

67 Oliver SJ, Moreira A, Kaplan G. Immune stimulation in scleroderma patients treated with thalidomide. Clin Immunol 2000;97:109-20.

68 Stevens RJ, Andujar C, Edwards CJ, et al. Thalidomide in the treatment of the cutaneous manifestations of lupus erythematosus: experience in sixteen consecutive patients. Br J Rheumatol 1997:36:353-9.

69 Hansen JM, Carney EW, Harris C. Differential alteration by thalidomide of the glutathione content of rat vs rabbit conceptuses in vitro. Reprod Toxicol 1999;13:547-54.

70 Newman CG. The thalidomide syndrome: risks of exposure and spectrum of malformations. Clin Perinatol 1986:13:555-73.

71 Neiger BL. The re-emergence of thalidomide: results of a scientific conference. Teratology 2000;62:432-5.

72 Parman T, Wiley M, Wells PG. Free radical-mediated oxidative DNA damage in the mechanism of thalidomide teratogenicity. Nat Med $1999 ; 5: 582-5$

73 Thiele A, Thormann M, Hofmann $\mathrm{HJ}$, et al. A possible role of N-cadherin in thalidomide teratogenicity. Life Sci 2000;67:457-61.

74 Stephens TD, Fillmore BJ. Hypothesis: thalidomide embryopathy-proposed mechanism of action. Teratology 2000;61:189-95.

75 Molloy FM, Floeter MK, Syed NA, et al. Thalidomide neuropathy in patients treated for metastatic prostate cancer. Muscle Nerve 2001;24:1050-7.

76 Ochonisky S, Verroust J, Bastuji-Garin S, et al. Thalidomide neuropathy incidence and clinico-electrophysiologic findings in 42 patients. Arch Dermatol 1994; 130:66-9.

77 Powell RJ, Gardner-Medwin JM. Guideline for the clinical use and dispensing of thalidomide. Postgrad Med J 1994;70:901-4.

For just US\$25 you can have instant access to the whole website for 30 days. During this time you will be able to access the full text for all issues (including supplements) available. You will also be able to download and print any relevant pdf files for personal use, and take advantage of all the special features Postgraduate Medical Journal online has to offer.

\section{www.postgradmedj.com}

